\title{
Memory for script-typical and script-atypical actions: A reaction time study
}

\author{
GLENN V. NAKAMURA \\ University of Illinois, Champaign, Illinois \\ and \\ ARTHUR C. GRAESSER \\ California State University, Fullerton, California
}

\begin{abstract}
Subjects listened to scripted activities (e.g., going to a restaurant) that contained typical actions (e.g., ordering a meal) and atypical actions (e.g., reading a newspaper). Recognition memory was measured at an immediate and at a delayed retention interval. The recognition memory test contained target and distractor test statements referring to actions that did or did not occur in the scripted activities. The latencies for yes-no recognition judgments were measured for these test statements. The memory and reaction time data supported the predictions made by a schemabased model.
\end{abstract}

A script is a knowledge structure that contains organized knowledge of the action sequences that typically occur in frequently enacted activities. For example, a restaurant script contains knowledge of the actions (e.g., the customer reads the menu, the customer orders, the customer eats, etc.) that typically occur during a customer's visit to a restaurant. Much of the past work on scripts has focused on memory for actions that are typical or atypical with respect to a script (Bellezza \& Bower, 1981; Bower, Black, \& Turner, 1979; Brewer \& Tenpenny, 1984; Graesser, Gordon, \& Sawyer, 1979; Graesser, Woll, Kolwalski, \& Smith, 1980; Light \& Anderson, 1983; Nakamura, Graesser, Zimmerman, \& Riha, 1985; Schank \& Abelson, 1977; Smith \& Graesser, 1981). One of the basic findings arising out of this past work is that recognition memory is better for atypical than for typical actions. Typical actions are those actions that normally or frequently occur in a scripted activity, whereas atypical actions are those actions that are irrelevant. They are not unusual, bizarre, or salient. For example, paying the bill is a typical action when one visits a restaurant, whereas reading a newspaper while waiting for the food is irrelevant when one visits a restaurant.

This research was supported by a National Institute of Mental Health grant (MH33491) to Arthur Graesser. The first author was a member of A. Graesser's Cognitive Research Group when the research reported here was conducted. In addition, the research benefited from discussions with members of the Cognitive Research Group (in particular, discussions with Leslie Clark, Tamar Murachver, Jim Riha, and Judy Zimmerman). Finally, portions of the article were presented by the first author at the 62nd annual meeting of the Western Psychological Association in Sacramento, CA, April 10, 1982. All correspondences regarding this article should be addressed to Glenn Nakamura, Department of Psychology, University of Illinois, 603 East Daniel, Champaign, IL 61820 .
Graesser (Graesser, 1981; Graesser et al., 1979; Graesser \& Nakamura, 1982; Graesser et al., 1980; Smith \& Graesser, 1981) has proposed a schema copy plus tag $(\mathrm{SC}+\mathrm{T})$ model that accounts for the better recognition memory for atypical than for typical actions. The SC $+\mathrm{T}$ model claims that typical actions that are either stated or unstated in a scripted activity are activated in the underlying script in memory. The unstated typical actions are assumed to be activated, because the underlying script guides inferencing during comprehension. For example, a person may infer while comprehending a restaurantscripted activity that a customer read a menu, but in fact the customer just ordered without reading the menu. In addition, the SC $+\mathrm{T}$ model claims that stated atypical actions are distinctively tagged in memory, whereas unstated atypical actions are not tagged in memory, because there is no script to infer them. According to the SC+T model, atypical actions should show good recognition memory, because it is easy to discriminate between atypical actions that are stored in memory and those that are not stored in memory. In contrast, there should be poor recognition memory for typical actions, because it is difficult to discriminate between those typical actions that were stated versus those that were unstated but inferred during comprehension.

The present experiment tested a prediction of the $\mathrm{SC}+\mathrm{T}$ model, which involved the reaction times associated with recognition memory for typical and atypical actions. The $\mathrm{SC}+\mathrm{T}$ model predicted that the reaction time to recognize whether an action was or was not stated in a scripted activity should be faster for atypical than for typical actions. The reaction times should be fast for atypical actions, because an atypical action is either stored or not stored in memory. In contrast, the reaction times for typical actions should be longer, because stated and unstated 
typical actions are activated in the underlying script. It should take time to determine whether the activation level of a typical action should lead to a yes or no recognition judgment.

\section{METHOD}

\section{Subjects}

The subjects were 32 male and female undergraduates at California State University, Fullerton. They participated in the experiment to fulfill an introductory psychology course requirement.

\section{Materials}

There were two passages (versions A and B), each of which stated the actions performed by a character named Jack as he enacted 10 scripted activities. Each of the two versions was tape recorded. Both versions contained the same scripted activities, which were presented in the following order: (1) barbecuing steaks, (2) getting up in the morning, (3) taking the dog to the vet, (4) cleaning the apartment, (5) washing the car, (6) going to a restaurant, (7) visiting the hospital, (8) going to the beach, (9) washing clothes at a laundromat, and (10) making an egg salad sandwich. The first and last scripts served as buffers.

For both versions, each of the eight experimental scripts contained a common set of 14 typical actions. However, there were 8 actions (4 typical and 4 atypical) in each of the eight scripts that were presented only in version A, but not in version B. Similarly, there were 8 actions (4 typical and 4 atypical) in each of the eight scripts that were only presented in version B, but not in version A. Thus, each version contained a unique set of 64 actions, 32 of which were typical and 32 of which were atypical. Altogether, there were 128 experimental actions when both versions were combined.

The typical actions of the scripts were originally generated by subjects in a previous study, whereas the investigators of that study generated the atypical actions (see Graesser et al., 1979, for details). Also, in that previous study a normative rating group rated each of the typical and atypical actions on a 6-point typicality scale. Across both versions, the 64 typical actions had a mean typicality rating of 5.41 (range $=4.40-6.00$ ), whereas the 64 atypical actions had a mean typicality rating of 2.84 (range $=1.90-4.20$ ).

The recognition memory test was administered after both a short and a long delay by a computer (Classic). At the short retention interval, one practice script (barbecuing steaks) and four experimental scripts were tested. At the long retention interval, one practice script (making an egg salad sandwich) and the four remaining experimental scripts were tested. For each subject, an $8 \times 8$ Latin square was used to determine the order in which the scripts should be tested.

Each of the eight experimental scripts was tested in a block of 16 actions, 8 of which were typical (4 typical-version $A$ and 4 typicalversion B) and 8 of which were atypical (4 atypical-version A and 4 atypical-version B). For each subject, a consistent testing order of the 16 test actions constituting each of the eight scripts was established by using a given row of a $16 \times 16$ Latin square.

\section{Procedure}

Acquisition. The subjects were tested individually in a quiet room that housed a computer. The subjects listened to a tape recording of version A or version B. An equal number of subjects listened to version A and to version B. After the passage was presented, the subjects engaged in several intervening tasks that took about $30 \mathrm{~min}$ to complete.

Recognition-reaction time. Following the completion of the intervening tasks, all of the subjects began the first of two recognition-reaction time sessions. The second session took place 2 weeks after the first session. For each session, the procedure involved one practice block followed by four test blocks. Each block contained a script title followed by a series of 16 test statements. A block began when a script title appeared on the screen. The subject pressed the return key, which caused the script title to disappear and the word READY to appear in its place. A recognition trial started when the subject pressed the return key again. After the subject pressed the return key, there was a pause before the word READY disappeared and an asterisk appeared in its place. The asterisk warned the subject that the test statement was to appear on the screen in $1 \mathrm{sec}$. After the onset of the test statement, the subject chose a response. The subject pressed the Y key to indicate "yes, this action was stated in the passage," and the $\mathrm{N}$ key to indicate "no, this action was not stated in the passage." After the subject pressed a key, the screen cleared and the word READY reappeared on the screen to signify that the next recognition trial was ready to be initiated.

\section{RESULTS}

For all analyses, the statistical level of significance was set at $\mathrm{p}<.05$.

\section{Recognition Memory Data}

Memory discrimination, as measured by $\mathrm{D}^{\prime}$, was better for atypical than for typical actions $[\mathrm{F}(1,31)=98.37$, MSe $=.47]$. In addition, memory discrimination was higher at immediate than at delayed testing $[\mathrm{F}(1,31)=$ $63.89, \mathrm{MSe}=.45]$. The interaction between typicality and retention interval was reliable $[\mathrm{F}(1,31)=24.89$, MSe $=.33$ ]. At immediate testing, memory discrimination was better for atypical (mean $=2.29$ ) than for typical (mean $=.58)$ actions $[\mathrm{F}(1,31)=75.32, \mathrm{MSe}=.33]$. Similarly, at delayed testing, memory discrimination was better for atypical $($ mean $=.84)$ than for typical $($ mean $=.14)$ actions $[\mathrm{F}(1,31)=23.92$, MSe $=.33]$. At delayed testing, this difference in memory discrimination between atypical and typical actions was smaller than at an immediate testing.

\section{Reaction Time Data}

The main effect of typicality was almost significant $[\mathrm{F}(1,31)=3.60, \mathrm{p}=.07, \mathrm{MSe}=.18]$. Reaction times were faster for atypical (mean $=2,112$ ) than for typical (mean $=2,181$ ) actions. In addition, there were significant effects of retention interval $[F(1,31)=30.20$, MSe $=.23]$, and response type $[\mathrm{F}(3,93)=15.29$, MSe $=$ .19]. Reaction times were faster at delayed (mean $=$ 2,030 ) than at immediate (mean $=2,263$ ) testing. The corresponding mean reaction times for hits, false alarms, correct rejections, and misses were 1,970, 2,105, 2,188, and 2,323 , respectively.

All three of the two-way interactions were significant: typicality $\times$ retention interval $[\mathrm{F}(1,31)=11.81$, MSe $=.14]$, typicality $\times$ response type $[\mathrm{F}(3,93)=2.87, \mathrm{MSe}$ $=.17]$, and retention interval $\times$ response type $[\mathrm{F}(3,93)$ $=4.58, \mathrm{MSe}=.17]$. The typicality $\times$ retention interval $X$ response type interaction was not significant $(F<1)$.

Follow-up analyses were performed to investigate the nature of the typicality $\times$ retention interval interaction. At immediate testing, atypical actions (mean $=2,171$ ) revealed faster recognition latencies than typical actions $($ mean $=2,354)[\mathrm{F}(1,31)=16.46$, MSe $=.14]$. However, at delayed testing, atypical actions (mean = 2,052 ) and typical actions (mean $=2,009$ ) did not differ in recognition latency $(F<1)$. The nature of the typicality $\times$ response type interaction at immediate as well as 
at delayed testing was informative. At immediate testing, a reaction time advantage of atypical over typical actions occurred uniformly for all four response types. In comparison, at delayed testing, the hits and false alarms had faster reaction times for typical than for atypical actions, whereas correct rejections and misses showed faster reaction times for atypical than for typical actions.

\section{DISCUSSION}

Memory discrimination was better for atypical than for typical actions at both an immediate and a delayed testing. These findings supported a major prediction of the SC $+\mathrm{T}$ model, and they replicate previous findings investigating memory for typical and atypical actions (e.g., Graesser et al., 1980; Smith \& Graesser, 1981). In general, the reaction time data supported a prediction of the SC $+\mathrm{T}$ model, which was that reaction times should be faster for atypical than for typical actions. This prediction was supported at immediate testing, and it held over different response types at immediate testing. However, at delayed testing, the reaction times were not faster for atypical than for typical actions, and there was not a consistent reaction time advantage for atypical actions across response types at delayed testing. Thus, these latter two findings were not in agreement with the reaction time prediction of the $\mathrm{SC}+\mathrm{T}$ model.

Future work could investigate whether the SC $+\mathrm{T}$ model could account for reaction times associated with recognition memory for information about persons. At present, the $\mathrm{SC}+\mathrm{T}$ model provides an account for why recognition memory is better for person-atypical than for persontypical information (Woll \& Graesser, 1982). However, associative models of person memory (Hastie, 1980; Srull, 1981; Srull, Lichtenstein, \& Rothbart, 1985) provide an alternative way of viewing and accounting for memory and reaction time data involving information about persons.

\section{REFERENCES}

BellezzA, F. S., \& Bower, G. H. (1981). The representational and processing characteristics of scripts. Bulletin of the Psychonomic Society, 18, 1-4.

Bower, G. H., BlaCk, J. B., \& TuRner, T. J. (1979). Scripts in comprehension and memory. Cognitive Psychology, 11, 177-220.
Brewer, W. F., \& TENPENNY, P. (1984). Schemas in human memory. Manuscript in preparation.

Graesser, A. C. (1981). Prose comprehension beyond the word. New York: Springer.

Graesser, A. C., Gordon, S. E., \& SaWyer, J. D. (1979). Recognition memory for typical and atypical actions in scripted activities: Tests of a script pointer + tag hypothesis. Journal of Verbal Learning \& Verbal Behavior, 18, 319-332.

Graesser, A. C., \& NAKAMURA, G. V. (1982). The impact of a schema on comprehension and memory. In G. H. Bower (Ed.), The psychology of learning and motivation: Advances in research and theory. New York: Academic Press.

Graesser, A. C., Woll, S. B., Kolwalski, D. J., \& Smith, D. A. (1980). Memory for typical and atypical actions in scripted activities. Journal of Experimental Psychology: Human Learning \& Memory, 6, 503-515.

HASTIE, R. (1980). Memory for information which confirms or contradicts a general impression. In R. Hastie, T. M. Ostrom, E. B., Ebbesen, R. S. Wyer, D. L. Hamilton, \& D. E. Carlston (Eds.), Person memory: The cognitive basis of social perception. Hillsdale, $\mathrm{NJ}$ : Erlbaum.

Light, L. L., \& ANDERSON, P. A. (1983). Memory for scripts in young and older adults. Memory \& Cognition, 11, 435-444.

Nakamura, G. V., Graesser, A. C., Zimmerman, J. A., \& Riha, J. (1985). Script processing in a natural situation. Memory \& Cognition, 13, 140-144.

SChANK, R. C., \& Abelson, R. (1977). Scripts, plans, goals, and understanding. Hillsdale, NJ: Erlbaum.

Smith, D. A., \& GrAesser, A. C. (1981). Memory for actions in scripted activities as a function of typicality, retention interval, and retrieval task. Memory \& Cognition, 9, 550-559.

SRULL, T. K. (1981). Person memory: Some tests of associative storage and retrieval models. Journal of Experimental Psychology: Human Learning \& Memory, 7, 440-463.

SRUll, T. K., Lichtenstein, M., \& Rothbart, M. (1985). Associative storage and retrieval processes in person memory. Journal of Experimental Psychology: Learning, Memory, \& Cognition. 11, 316-345.

Woll, S. B., \& Graesser, A. C. (1982). Memory discrimination for information typical or atypical of person schemata. Social Cognition, 1, 287-310.

(Manuscript received for publication June 3, 1985.) 